\title{
Instructional Design and Training of Typical Simulation Project -- water supply and monitoring system
}

\author{
Yafeng. Zhang \\ Qinghai Architectural Vocational and Technical College, Xining , 810012,China \\ email: lovetha@163.com
}

Keywords: Typical simulation project; Water supply equipment installation; Connections; monitoring;Operation adjustment

\begin{abstract}
In order to foster students' ability of analyzing and solve problems and improve their practical ability, we designed a comprehensive practical instructional simulation which helps the students to have a clear understanding of water supply and monitoring theory based on the curriculum. This simulation combines the water supply project and its monitoring system tightly.

The students should be able to complete the installation and adjustment of the simulation after finishing the related courses such as " water supply and drainage engineering ", " electric control ", " pipe installation process ", " electric construction technology " and the installation of pipelines.

Among the numerous ways of water supply, the combination of pool, water tank and pump is widely used. So we choose this typical combination as our simulation course. The main function of monitoring is to control the pump by computer to optimize the system and fulfill a high-efficient but economic operation. The water level in the tank and the pump status are the key parts to be monitored.
\end{abstract}

\section{Designing and implementation of a water supply project and its monitoring system.}

The system combined with the characteristics of water supply, give full consideration to the students' basic skills and raised the requirements on technology, economy, safety and the designing, material selection, facility and implementation on intelligent buildings.

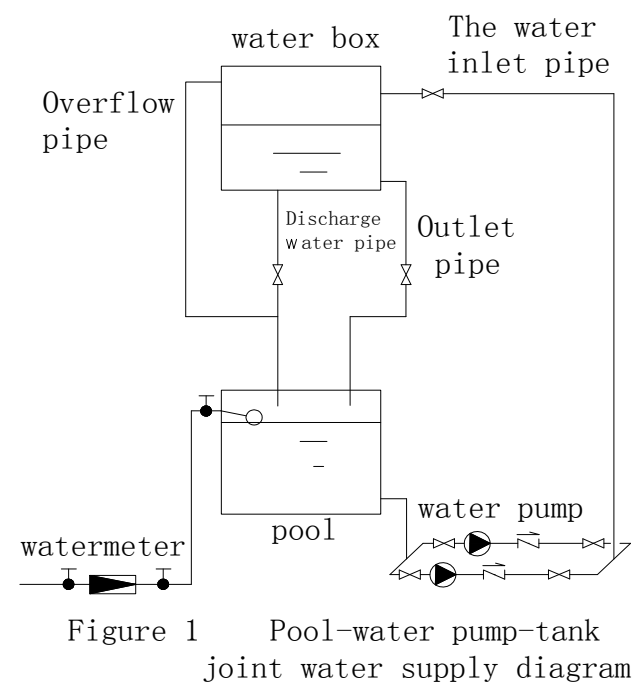

A. Water supply system engineering

1) Pool and water tank

Set two tanks of 0.2 cubic meters, one work as pool. Make the frames, set up and fix the pool and water tank.

2) Water pump

Model: 1DBZ35; head: 35 (m ) ; flow rate: 40L/min, install the pump properly. 
3) Pipeline and attachments

Install the pipeline, valve and the attachments according the diagram.

B. Tthe project monitoring system

1) DDC controller

DDC controller produced by Shenzhen Songda Technology Co. Ltd., is suitable for the simulation. Two models will be used in this system. One is ST-DIO-0808, for the collection and control of the switch quantity. The other is ST-AIO-0804, for the collection and control of the analog signal.

2) Water level switch

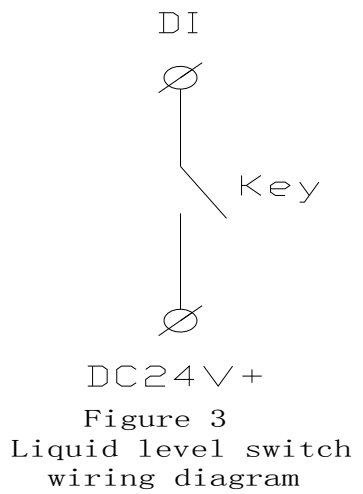

Installation: series connect the water level switch to DI of the DDC controller ST-DIO-0808. There are 3 lines on the switch, NC for normally closed, NO for normally open, COM for public end respectively. It's ok to connect to any line. Just take the reversed data in the configuration. For example, if series connect NC to COM and the original data of lower level of DI is 1 , thus the higher level should be 0 . If series connect NO to COM and the original lower level of DI is 0 , thus the higher level should be 1 . These can be the factor to start the water pump. Liquid level control is decided by the cable length in water and position of weight dropper on cable.

3) Main circuit diagram

Connect the pump according to the main circuit diagram.
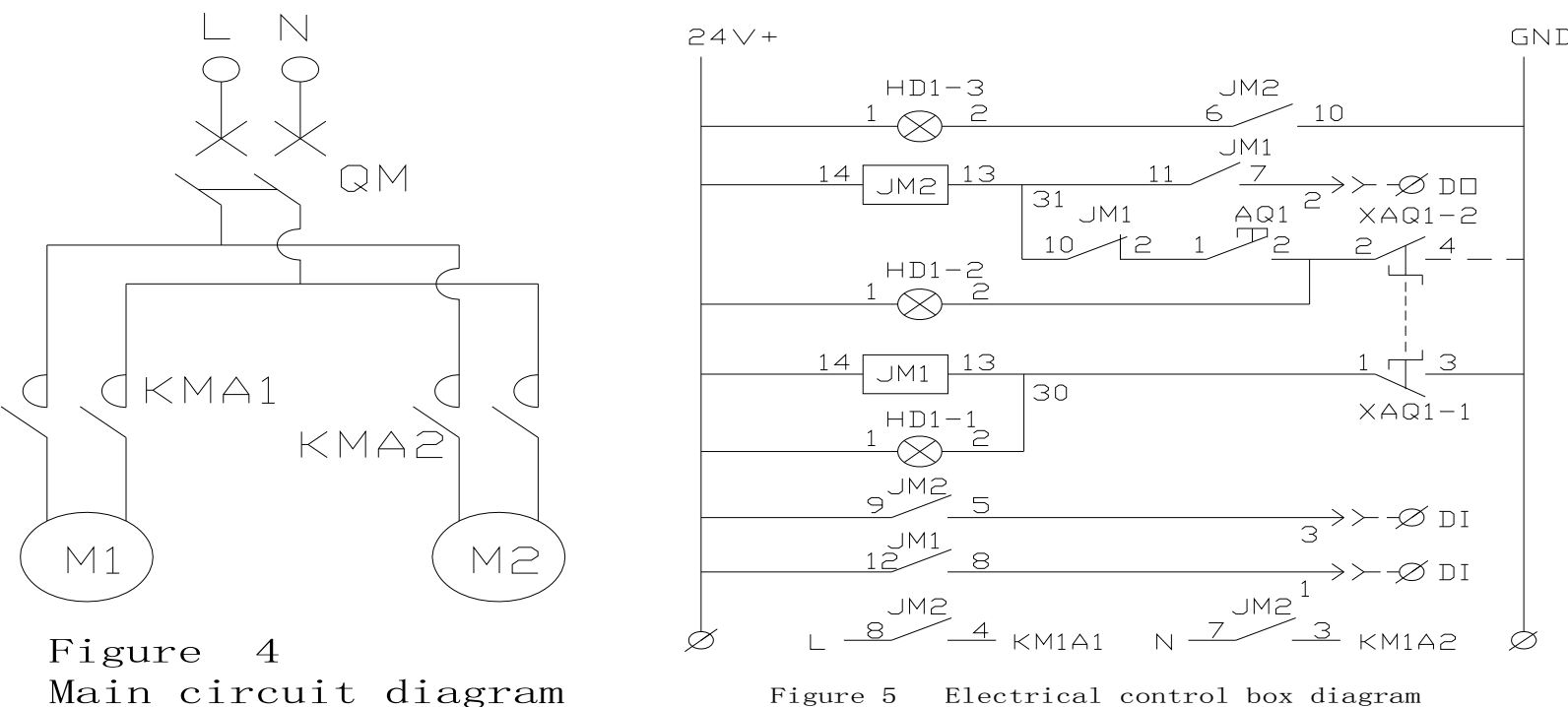

4) Electric control box

a) The electric control box can be used through manual / automatic control conversion to achieve a box of low-voltage control high voltage, weak current control strong one. Mainly consists by leakage protector, 
b) DC24V transformer, electric relay, AC contactor, automatic/manual switch, button and indicator.

c) The principle of electrical control box

- Manual control

To turn to manual module by turning XAQ1-2 to GND and HD1-2 manual indicator light goes on. Press AQ1, GND connects the 13th end of JM2 through JM1. JM2 gets electricity and the four groups of normally open contacts closed $(6,10,5,9,4,8,3,7$ ), HD1-3 running lights, JM2 normally open contact 24V+ to DDCDI for the operation DI, JM2 (220V) L 8 pin, 7 pin ( 220V ) N, 3 feet, 4 feet are respectively connected to the coil of the AC contactor KM1 KM1A1 and KM1A2, and KM1 have electric action, contact pull-in pump action KM1.

- Automatic control

Turn XAQ1-1 to automatic modal on the GND, HD1-1 automatic indicator goes on. The four groups of normally open contacts of JM1 closed, and the manual control modal closed meanwhile. We use 2 groups only (7.11,8.12) and connect 7 to DDCDO, 11to JM2 of 13th end. Connect the normally open point 8 and 12 to DDCDI through $24 \mathrm{~V}+$. When the DO is output, JM2 can complete the automatic control. M2 pump control principles are the same.

5) Design System Monitoring table

TABLE 1 DESIGN SYSTEM MONITORING TABLE

\begin{tabular}{|l|l|l|l|l|}
\hline \multirow{2}{*}{ The device name and control function } & input & \multicolumn{3}{l|}{ output } \\
\hline & DI & AI & DO & AO \\
\hline To start the pump & & & 4 & \\
\hline To the running state of water pump & 4 & & & \\
\hline Feed water pump water supply status & 5 & & & \\
\hline Start pump water level & 2 & & & \\
\hline Low water level alarm & 2 & & & \\
\hline Stop pump water level & 2 & & & \\
\hline
\end{tabular}

Monitoring the pump status and fault alarm ( DI ); water pump switch status ( DI ); operation status of pump and fault alarm ( DI ); control pump to start and stop ( DO ). This is a spot table, namely the DO and DI number of the system. Only when the DDC is connected to the computer, could the control function be fulfilled through the normally open contact of $24 \mathrm{~V}$ positive for DI, DO of DDC control the relay box, write a program to achieve the group state control.

6) Controlling software

The Beijing group configuration control version 6.53, compiling and communication and control the DDC daemon.

\section{The comprehensive training}

A. Training task

1) Water supply engineering installation;

2) Monitoring system installation;

3) Programming and adjusting, water supply system monitoring.

B. The training equipment, tools

TABLE II EQUIPMENTS AND TOOLS TABLE

\begin{tabular}{|l|l|l|c|}
\hline Name & Type & Quantity & Remarks \\
\hline tank ( pool) & Made & 2 & Stainless steel 500*600*600mm \\
\hline double simulation frame & Made & 1 & iron, painting \\
\hline main pump ( auxiliary pump ) & 1DBZ35 & 2 & power 335W, head: 35 m \\
\hline cut-off valve & DN25 & 10 & DN25 \\
\hline
\end{tabular}




\begin{tabular}{|l|l|l|l|}
\hline check valve & DN25 & 5 & DN25 \\
\hline level switch ball float type & DN25 & 2 & DN25 \\
\hline level switch ball float type & S6025 & 2 & ball float type \\
\hline pipe & DN25 & 10 & PVC \\
\hline DDC controller & ST_AI0_0808 & 2 & sunda \\
\hline electric control box & Made & 1 & \\
\hline
\end{tabular}

C. Tthe training process

1) water supply system equipment installation.

a) Install the equipment according to the design of water supply system.

- In the specified location, fixed double simulation frame.

- Fix the simulation pool under the frame and fix the water tank above the frame, pay attention to the direction of the water pipe.

- Make clear the direction of water in and out, pay attention to the direction and position. Fix the pumps on the frame with bolts.

b) The pipe connection between devices and double check.

- Measure the length of pipe and cut the pipes needed. (need to add up the interface length of connecting pipe ).

- Use sandpaper to clean the inside and outside of interface thoroughly, smear qualified glue, insert the pipe when the glue is dry.

- The quantity and position of fixing clips, pipe accessories must be based on the correct setting of site condition and repair requirements.

2) The installation of 2 monitoring system

a) Connect the DDC controller to the equipment according to the system monitoring points.

b) To avoid misconnections, pay attention to the mark of connecting points of electricity and signal lines.

3) Programming and debugging.

a) Correct installation and configuration software.

b) Configuration software connection settings, set up equipment connection, connection and field corresponds to the DDC.

c) The establishment of a database and define variables.

d) Design and programming, the configuration screen monitor debugging.

4) System debugging.

a) Close the inlet valve after the pool is full.

b) Control system check before electricity goes on; be sure to check carefully. Wait the teacher to give the final check.

c) Check the grim voltage to see if it agrees with the equipment voltage requirements. To check immediately after turning on the power to see if smoke or smell happens, turn off the power if it's positive.

d) Start the debugging if no exceptions happens on step 3. In manual work condition, push the pump start button, check the pump works well. And then switch to automatic status; check the control of pump by water level.

e) Observe the program operation on the control computer, complete the system debugging.

5) Summary

a) Understand the principle, drawing, can identify the diagrams.

b) Understand the equipments, accessories and carefully read the instructions.

c) Using the tools correctly.

d) Implement the installations correctly.

e) Know what and how to inspect, to think while practicing, encourage innovation. 


\section{Conclusion}

This system can be used for demonstration of water supply system, operation and programming of DDC controller, design and connection of water supply pipes, test and train the system defaults. It can not only show the students the equipments and it's principle, structure and components, but also train the students to get practical experience and ability of installation and debugging through this simulation. And to constantly improve their technical level to meet the needs of the enterprises.

\section{References}

[1] Jian.Zhang, Building water supply and drainage engineering, Architectural industry press, 2005.

[2]Xiaoyuan.Hu, Electrical control technology on construction, Building industry press, 2005.

[3]Hongliang.Mo, Installation process piping, Labor and social security press of China, 2000.

[4]Chushe.Xie, Construction technology, construction electrical, Wuhan University of Technology press, 2008.

[5]Jieting. Wei, Building Equipment, Wuhan University of Technology press ,2004. 